\title{
The Fermilab Main Injector Dipole Construction Techniques and Prototype Magnet Measurements
}

M. Bleadon, B. Brown, N. Chester, E. Desavouret, J. Garvey, H. Glass, D. Harding, F. Harfoush, S. Holmes, J. Humbert, J. Kerby, A. Knauf, G. Kobliska, A. Lipski, P. Martin, P. Mazur, D. Orris, J. Ostiguy, S. Peggs, J. Pachnik, E. Pewitt, J. Satti, E. Schmidt, J. Sim, S. Snowdon, and D. Walbridge

Fermi National Accelerator Laboratory

P.O. Box 500, Batavia, Illinois 60510

September 1991

* Presented at the 12th International Conference on Magnet Technology, Leningrad, USSR, June 23-28, 1991. 


\section{The Fermilab Main Injector Dipole}

\section{Construction Techniques and Prototype Magnet Measurements}

M. E. Bleadon, B. C. Brown, N. S. Chester, E. Desavouret, J. D. Garvey, H. D. Glass, D. J. Harding, F. A. Harfoush, S. D. Holmes, J. C. Humbert, J. S. Kerby, A. B. Knauf, G. R. Kobliska, A. Lipski, P. S. Martin, P. O. Mazur, D. F. Orris, J.-F. Ostiguy, S. G. Peggs, J. E. Pachnik, E. G. Pewitt, J. A. Satti, E. E. Schmidt, J. W. Sim, S. C. Snowdon, and D. G. Walbridge Fermi National Accelerator Laboratory * P.O. Box 500, Batavia, Illinois 60510

\section{Abstract}

The Fermilab Main Injector Project will provide 120$150 \mathrm{GeV}$ Proton and Antiproton Beams for Fermilab Fired Target Physics and Colliding Beams Physies use. A dipole megnet has been designed and prototypes constructed for the principal bending magnets of this new accelerator. The design considerations and fabrication techniques are described. Measurement results on prototypes are reported, emphasizing the field uniformity achieved in both body field and end field at excitation levels from injection at $0.1 \mathrm{~T}$ to full field of $1.7 \mathrm{~T}$.

\section{Introduction}

The Fermilab Main Injector is designed to replace the Fermilab Main Ring for both Tevatron injection and for production of antiprotons. It will also provide a high intensity source of protons which can be used for particie physics or as a source of test beams during collider physics operations.[1][2]. Conventional dipole magnets, with a core of iron laminations and a conduetor of water-cooled copper, provide the primary bending for this accelerator. The lattice design uses two dipole magnet lengths: a 6-meter dipole and a 4-meter dipole. The machine can run as rapidly as 1.5 seconds/cycle during antiproton production. The basic magnet parameters are presented in Table 1. Extensive measurements have been made on the first 6-meter prototype magnet. A second prototype has exercised all fabrication steps except final magnet assembly with completion expeeted in June 1991.

\section{Design Requirements}

The design of the Main Injector synchrotron imposes design requirements on this magnet. [3] Special design considexation is given to the fields at injection $(0.1 \mathrm{~T})$, transition

\footnotetext{
- Operated by the Universities Resenreh Association under contract with the U. S. Department of Energy
}

\begin{tabular}{|l|c|c|}
\hline & "240-inch" & "160-inch" \\
\hline Sagitta & $16 \mathrm{~mm}$ & $7 \mathrm{~mm}$ \\
\hline Number & 216 & 128 \\
\hline Gap & \multicolumn{2}{|c|}{$5.08 \mathrm{~cm}(2$ inch) } \\
\hline Marimum field & \multicolumn{2}{|c|}{$1.73 \mathrm{~T}$} \\
\hline Weight & $17000 \mathrm{~kg}$ & $12000 \mathrm{~kg}$ \\
\hline Laminations & 8000 & 5333 \\
\hline Conductor & $25.4 \times 101.6 \mathrm{~mm}^{2}$ coppez \\
\hline Cooling water & $12.7 \mathrm{~mm}$ dis. hole, $0.68 \mathrm{l} / \mathrm{s}$ \\
\hline Maximum current & \multicolumn{2}{|c|}{$9375 \mathrm{~A}$} \\
\hline Resistance & $0.8 \mathrm{~m} \Omega$ & $0.6 \mathrm{~m} \Omega$ \\
\hline Inductance & $2.0 \mathrm{mH}$ & $1.3 \mathrm{mH}$ \\
\hline Maximum ramp & $240 \mathrm{GeV} / \mathrm{sec}(15000 \mathrm{~A} / \mathrm{sec})$ \\
\hline Peak power & $75 \mathrm{~kW}$ & $50 \mathrm{~kW}$ \\
\hline
\end{tabular}

Table 1: Main Injector Dipole Parameters

(0.22 T), $120 \mathrm{GeV}$ slow extraction and antiproton production (1.38 $\mathrm{T}$ ), and $150 \mathrm{GeV}$ fast extraction for Tevatron Injection (1.72 $\mathrm{T}$ ). The cross section selected is shown in Figure 1.

The good field requirements vary through the accelerator cycle. We require that the field deviate no more than one part in $10^{4}$ over a region that depends on the beam size. The required good field apertures are shown in Table 2. We require also that the deviations from a uniform field be dominated by the sextupole field component to permit compensation of the errors by the sertupoles alone, avoiding higher order correction elements. The design combines an adequate field shape uniformity in the body with a "neutral" end field ${ }^{1}$. Measurements of the prototype magnet confirm the end field computations discussed in [4].

The pole tip shape varies from flat with a slight reduction of the gap ("shims") at large $x$. This produces a small positive sextupole component in the field at low and intermediate fields and partially compensates for the saturation at higher fields. (The net sextupole is 0 at approximately $0.83 \mathrm{~T}$.) The tapered pole piece reduces non-uniform satu-

\footnotetext{
${ }^{1}$ A "neatral" end has anficient aniformity of the integrated bend field to neither enhance nor cancel body field non-uniformities.
} 


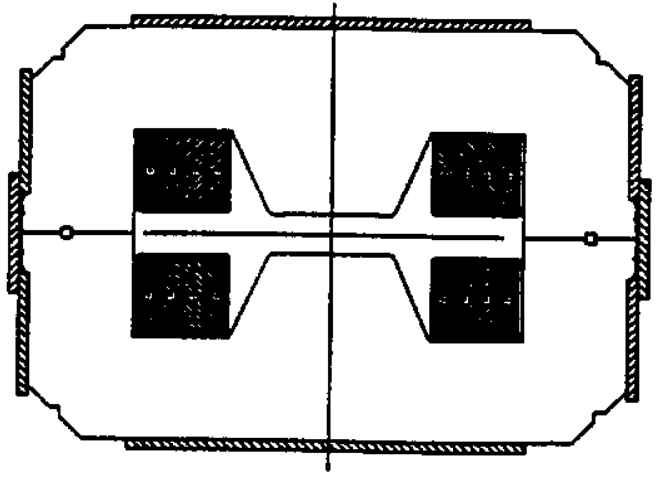

Figure 1: Cross section of Main Injector Dipole

\begin{tabular}{|r|r|r|r|}
\hline Energy & Field & Horizontal & Vertical \\
\hline \hline $8 \mathrm{GeV}$ & $0.1 \mathrm{~T}$ & $\pm 22 \mathrm{~mm}$ & $\pm 21 \mathrm{~mm}$ \\
\hline $19 \mathrm{GeV}$ & $0.22 \mathrm{~T}$ & $\pm 34 \mathrm{~mm}$ & $\pm 16 \mathrm{~mm}$ \\
\hline $120 \mathrm{GeV}$ & $1.38 \mathrm{~T}$ & $\pm 30 \mathrm{~mm}$ & $\pm 9 \mathrm{~mm}$ \\
\hline $150 \mathrm{GeV}$ & $1.72 \mathrm{~T}$ & $\pm 10 \mathrm{~mm}$ & $\pm 9 \mathrm{~mm}$ \\
\hline
\end{tabular}

Table 2: Required good field region as a function of energy for the Main Injector Lattice, March 1991 (MI16) .

ration at the base of the pole and thus reduces the magnitude of the multipoles induced by saturation. This assists in maintaining a sufficient good field width for slow resonant beam extraction. At high fields, nevertheless, the sextupole becomes increasingly negative, since saturation tends to weaken the fieid near the edge of the apezture.

The remanent field (12 gauss), while not negligible, is sufficiently uniform so as to cause little contribution to the field shape variation with current. This is also in part due to the tapered poles since all the material at the base of the pole has a sufficiently similar magnetic history during excitation.

The geometrical aperture is improved by building eurved magnets. The bending radius of the beam in the dipoles is about 290 meters. This produces an offset of $16 \mathrm{~mm}$ from the center line in the middle of a 6-meter dipole and an offset of $7 \mathrm{~mm}$ in the 4-meter dipoles. The magnet laminations, the good field region, and the beam pipe will follow that bend. The magnet will be fabricated entirely from laminations, so the ends will be parallel, (each at an angle of about $0.6^{\circ}$ from the radius for the 6-meter magnets). The resulting variation in the bend for particles of various offsets from the nominal orbit is partially compensated by the end pack design.

To reduce operating costs, a large cross sectional area of copper is used. To reduce the voltages required for high ramp rates, only four turns per pole are used, requiring almost $9400 \mathrm{~A}$ to achieve $1.7 \mathrm{~T}$. To reduce the requirements for copper buswork in the tunnel, each magnet is designed as a four-lead device containing a half turn "through-bus" which connects to adjacent magnets.

\section{Fabrication of Core}

The laminations are punched from a $1.5 \mathrm{~mm}$ low carbon steel which is specified to have $H_{c}<1.0 \mathrm{Oc}$ and a permeability of $180 \pm 1$ gauss/Oe at $H_{m}=100 \mathrm{Oe}$. The laminations are electrically insulated with a thin epoxy coating to reduce eddy currents. $150 \mathrm{~mm}$ thick end packs are built from regular laminations which are epoxied together to provide strength to resist both spring forces during assembly and magnetic forces during operation. The special end shape[4] is achieved by trimming ("nibbling") about 30 of these laminations to the proper contours before assembly of the end pack so that the final shape produces the desired field. The core is assembled by stacking against a curved template rail, beginning and ending with a preglued end pack. With the laminations held under pressure by a screw press, side and top plates are welded on to hold the half-core together. After installation of the coils, the two half cores are welded together. Each magnet is supported at two longitudinal points chosen to minimize the vertical displacement.

\section{Fabrication of Coils}

Many of the failures found in existing Fermilab dipoles occur at conductor joints within the coil. To provide a more reliable design, the number of joints has been reduced and improved techniques are used to braze the joints. The stresses on the coil joints are also reduced by allowing the coil to expand longitudinally in response to thermal cycles, rather than potting it in the core.

There are four turns of $25.4 \mathrm{~mm} \times 101.6 \mathrm{~mm}$ conductor per pole with no conductor in the median plane. This simplifies the end design by allowing the coil to be a plain pancake design rather than a saddle. The coils are assembled from 6-meter bars. The joints between conductor segments are brased after counterboring at the water holes to insert a ferrule. Similar joints have proved their reliability in recent years.

Coil insulation is provided by fiberglass tape wrapped on the conductors and potted using a thermal cure epoxy. G10 sheets are included in the coil to provide further mechanical strength as well as electrical insulation. The entire package is vacuum impregnated with epoxy and cured in a mold shaped to match the core sagitta. Figure 2 illustrates the insulation scheme. The columns of Table 3 describe the coil-to-coil, coil-to-bus, and outer ground wrap insulation system details. Fiberglass tape (0.18 mm thick) 


\begin{tabular}{|l||c|c|c|}
\hline $\begin{array}{l}\text { Insulation } \\
\text { Layer }\end{array}$ & $\begin{array}{c}\text { Coil } \\
\text { Insulation }\end{array}$ & $\begin{array}{c}\text { Bus } \\
\text { Insulation }\end{array}$ & $\begin{array}{c}\text { Ground } \\
\text { Insulation }\end{array}$ \\
\hline \hline Inner Wrap & Butt Wrap & Half Lap & $\begin{array}{c}2 \text { Layers } \\
\text { Half Lap }\end{array}$ \\
\hline G10 Layer & sides & sides & next to core \\
\hline Outer Wrap & Half Lap & Half Lap & Half Lap \\
\hline
\end{tabular}

Table 3: Coil Insulation Details. Each wrap layer consists of $0.18 \mathrm{~mm}$ glass fiber. G10 in coil is $0.38 \mathrm{~mm}$ thick.
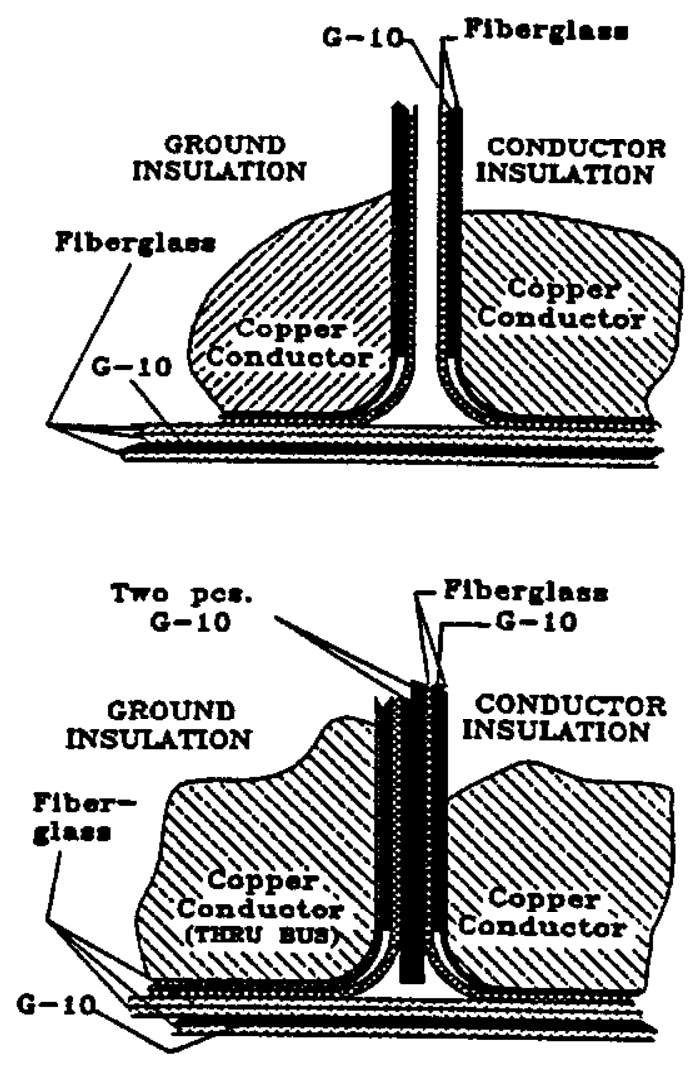

Figure 2: Coil to Coil (top) and Coil to Bns insulation sehemes. Butt lapped and half lapped glass tape (0.18 $\mathrm{mm}$ thick) and $0.38 \mathrm{~mm}$ G10 Fiber Glass Epoxy composite create the insulation structure.

is used in either butt wrapped or half-lapped configurations to achieve suitable mechanical and electrical properties. A nominal .76 mm space between coils allows for mechanical variation of the copper. This space is filled with epoxy in the potting operation. The insulation system will withstand up to 5000 voits between coil and bus as well 2000 volts to ground.

By using a kapton layer between the coil and the core, one achieves a further ground insulation and also provides a slip plane to allow the coil to move in the core upon thermal expansion of either component. The coil is anchored in the center of the core with a 1 m long epoxy bead. To

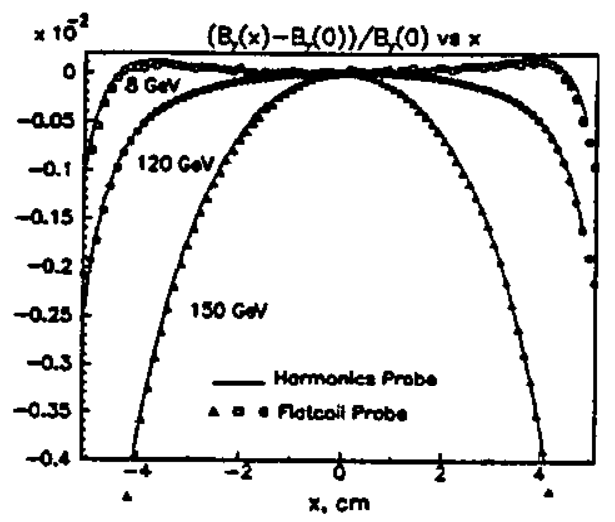

Figure 3: $B_{Y}(x)$ for Main Injector Dipole at Injection, $120 \mathrm{GeV}$, and $150 \mathrm{GeV}$

support the coil against transverse Lorentz forces, a G10 layer is installed against the kapton on the vertical edges of the coil adjacent to the core and the remaining void between the G10 sheet and the core is filled with epoxy.

While assembling two half-cores to create a dipole, the coils are supported with polyurethane blocks of sufficient length to elastically support the coil weight. Final support for the coils is created using G10 spacers with an epoxy filler inserted upon assembly. The series connection of upper and lower coils is made by two symmetrical parallel conductors which each carry half the current. Connections are accomplished with a brazing operation. Magnet to magnet connections in the tunnel utilize bolted copper joints.

\section{Magnetic Field Measurements}

At the Fermilab Magnet Test Facility, we have measured the field of the prototype magnet as a function of current using standard point (Hall probe and NMR) and integrating (rotating coil and rigid non-rotating "FLATCOIL") techniques[5]. We have measured the body field of the first prototype magnet to validate the lamination design. The measured magnetic field shape is plotted in Figure 3 for injection, $120 \mathrm{GeV}$, and $150 \mathrm{GeV}$.

Figute 4 shows the field variation of $B_{Y}(x)$ at $y=0$ for $B(0)=0.10 \mathrm{~T}$. Shown are the field as calculated $[6]$, as measured with the flatcoil system, and as reconstituted from three rotating coil harmonic measurements. The agreement is strikingly good among measurements and with calculation on and off the midplane both here and through the range of field strengths where the steel remains, at most, only mildly saturated. At high fields we find the agreement among the measurement techniques to remain excellent. The agreement with calculation is not as good. 


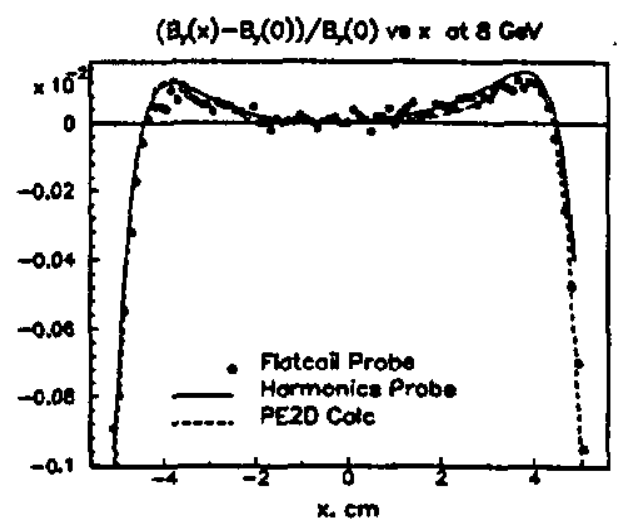

Figare 4: $B_{Y}(x)$ at $\mathrm{y}=0 \mathrm{~cm}$ and $\mathrm{B}(0)=0.10 \mathrm{~T}$ computed, measured with flatcoil, and recreated from harmonics

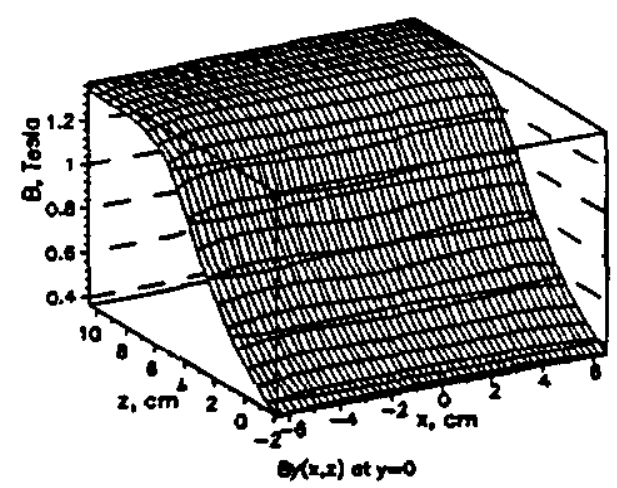

Figure 5: $B_{y}$ in a region on the $y=0$ plane near the end of the magnet.

To assist in understanding the end pack design we have studied the magnetic field in the end using a Hall probe system which is seanned in the end field volume. A typical result is shown in Figure 5. Systematic studies with FLATCOIL and rotating coil systems inserted to various depths have measured the integrated error field contributions of the end. We conclude that the end field shape design produces small contributions to the field shape errors.

\section{Acknowledgements}

Many groups at Fermilab have contributed to this work. We would especially like to thank Steve Barath, Don Rissman, Howard Dixon, Jim Jablonski for magnet design and fabrication work; Ray Carra and Don Olson for measurement system design efforts; and Shree Agrawal, Steve Helis, Keith Dillow, Cervando Castro, Butch Bianchi, Dave Hartness, Mike Cherry, Mark Thompson, and Dean Validis for measurement system fabrication and testing efforts.

\section{References}

[1] S. D. Holmes. Achieving high luminosity in the Fermilab Tevatron. In Proceedings of the IEEE 1991 Particle Accelerator Conference.

[2] Fermilab Upgrade: Main Injector. Conceptual Design Report, March 1991. Revision 2.3, Addendum.

[3] D. J. Harding, M. E. Bleadon, B. C. Brown, E. Desavouret, J. D. Garvey, H. D. Glass, F. A. Harfoush, S. D. Holmes, J. C. Humbert, J. M. Jagger, G. R. Kobliska, A. Lipski, P. S. Martin, P. O. Mazur, F. E. Mills, D. F. Orris, J.-F. Ostiguy, S. G. Peggs, J. E. Pachnik, E. E. Schmidt, J. W. Sim, S. C. Snowdon, and D. G. Walbridge. Design considerations and prototype performance of the Fermilab Main Injector dipole. In Proceeding of the 1991 IEEE Particle Accelerator Conference, San Francisco, May 6-9, 1991. Institute of Electrical and Electronic Engineers, 1991.

[4] J.-F. Ostiguy. Magnet end design: The Main Injector dipoles. In Proceedings of the IEEE 1991 Particle Accelerator Conference.

[5] Bruce C. Brown. Fundamentals of magnetic measurements with illustrations from Fermilab experience. In P. F. Dahl, editos, Proceedings of the ICFA Workshop on Superconducting Magnets and Cryogenics, page 297. Brookhaven National Lab, 1986.

[6] Jean-François Ostiguy. Main Injector dipole magnet: 2D field computations. Technical report, Fermilab Main Injector Note, October 1990. MI0036. 